\title{
Observability of fine-scale ocean dynamics in the northwestern Mediterranean Sea
}

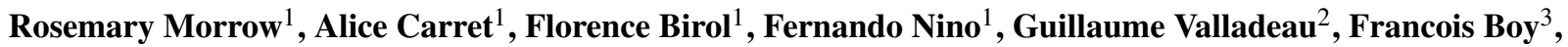 \\ Celine Bachelier ${ }^{4}$, and Bruno Zakardjian ${ }^{5,6}$ \\ ${ }^{1}$ LEGOS, IRD, CNRS, Université de Toulouse, Toulouse, 31400, France \\ ${ }^{2}$ CLS Ramonville, St.-Agne, 31520, France \\ ${ }^{3}$ CNES, Toulouse, 31400, France \\ ${ }^{4}$ IRD, Brest, 29280, France \\ ${ }^{5}$ Université de Toulon, CNRS, IRD, Mediterranean Institute of Oceanography (MIO), UM 110, 83957 La Garde, France \\ ${ }^{6}$ Aix Marseille Université, CNRS, IRD, Mediterranean Institute of Oceanography (MIO), UM 110, 13288 Marseille, France
}

Correspondence to: Rosemary Morrow (rosemary.morrow@legos.obs-mip.fr)

Received: 2 August 2016 - Published in Ocean Sci. Discuss.: 20 September 2016

Revised: 9 December 2016 - Accepted: 13 December 2016 - Published: 13 January 2017

\begin{abstract}
Technological advances in the recent satellite altimeter missions of Jason-2, SARAL/AltiKa and CryoSat-2 have improved their signal-to-noise ratio, allowing us to observe finer-scale ocean processes with along-track data. Here, we analyse the noise levels and observable ocean scales in the northwestern Mediterranean Sea, using spectral analyses of along-track sea surface height from the three missions. Jason-2 has a higher mean noise level with strong seasonal variations, with higher noise in winter due to the rougher sea state. SARAL/AltiKa has the lowest noise, again with strong seasonal variations. CryoSat-2 is in synthetic aperture radar (SAR) mode in the Mediterranean Sea but with lower-resolution ocean corrections; its statistical noise level is moderate with little seasonal variation. These noise levels impact on the ocean scales we can observe. In winter, when the mixed layers are deepest and the submesoscale is energetic, all of the altimeter missions can observe wavelengths down to $40-50 \mathrm{~km}$ (individual feature diameters of $20-25 \mathrm{~km}$ ). In summer when the submesoscales are weaker, SARAL can detect ocean scales down to $35 \mathrm{~km}$ wavelength, whereas the higher noise from Jason- 2 and CryoSat- 2 blocks the observation of scales less than $50-55 \mathrm{~km}$ wavelength.

This statistical analysis is completed by individual case studies, where filtered along-track altimeter data are compared with co-located glider and high-frequency (HF) radar data. The glider comparisons work well for larger ocean structures, but observations of the smaller, rapidly moving
\end{abstract}

dynamics are difficult to co-locate in space and time (gliders cover $200 \mathrm{~km}$ in a few days, altimetry in $30 \mathrm{~s}$ ). HF radar surface currents at Toulon measure the meandering Northern Current, and their good temporal sampling shows promising results in comparison to co-located SARAL altimetric currents. Techniques to separate the geostrophic component from the wind-driven ageostrophic flow need further development in this coastal band.

\section{Introduction}

The ocean circulation in the northwestern Mediterranean Sea exhibits widespread mesoscale dynamics, with strongest values along the Northern Current which flows westwards along the French coast following the continental slope (Millot, 1999; Guihou et al., 2013). Observing the mesoscale variability is critical in this region since it plays a key role in the coupled ocean-atmospheric system that can lead to extreme precipitation events (Lebeaupin Brossier et al., 2015). Horizontal currents stirred by the mesoscales are important in the dispersion of pollutants and the monitoring of marine ecosystems. The vertical transport of heat, salt and nutrients is strongly driven by the smaller-scale dynamics, in the fronts and filaments surrounding these mesoscale eddies, and within the deep convection cells that form in the Gulf of Lyons in winter-spring (Herrmann et al., 2008). 
Compared to other current systems at similar latitudes such as the Gulf Stream, the mesoscale variability in the northwestern Mediterranean Sea has a small Rossby radius of 5-15 km, varying seasonally with the stratification (Grilli and Pinardi, 1998). This makes the ocean dynamics of this region particularly difficult to observe and monitor. The surface mesoscale characteristics have been studied with satellite sea surface temperature (SST) and ocean colour data in clearsky conditions (Robinson, 2010), but the mesoscale variability is often hidden in winter by clouds and in summer under the more homogenous warm surface layer. Numerical modelling studies are improving in resolution and in their internal physics to allow a better representation of the mesoscale variability (e.g. Herrmann et al., 2008), although these models need to be validated against observations.

In the global ocean, mapped satellite altimeter products have allowed unprecedented advances in understanding the mesoscale eddy variability and characteristics (Chelton et al., 2011). Altimetry measures sea surface height (SSH) that responds to mass and density changes over the entire water column, and as such, altimetry is the only satellite observation that can detect deep ocean changes. Deep-reaching mesoscale eddies can be tracked over many seasons or years (e.g. Morrow et al., 2004; Chelton et al., 2011), even if their surface signature disappears through air-sea interactions so that they become undetectable in satellite imagery. Although regional altimeter maps have been constructed with improved resolution and spatial scales adapted for the Mediterranean Sea (e.g. Pujol and Larnicol, 2005), the spacing between ground tracks still limits our ability to monitor scales less than $150 \mathrm{~km}$ wavelength (or $75 \mathrm{~km}$ diameter features) (Pascual et al., 2006). Thus we can only detect the larger mesoscale structures, missing most of the typical Rossby radius dynamics in the Mediterranean Sea.

Along-track altimeter data are able to detect finer scales than the mapped altimeter data, but the spatial scales we can resolve are still limited by the altimeter noise, the accuracy of the corrections and the processing methodology. However, over the last 5 years, there has been great progress in improving the quality of along-track satellite altimeter data for ocean studies. Of the three missions currently flying in the altimeter constellation, Jason- 2 in $\mathrm{Ku}$-band (launched in 2008) has benefitted from continually refined algorithms and corrections, and new waveform retrackers that allow more data points to be collected close to the coast and islands, and more stable performance with lower noise over the oceans (Dibarboure et al., 2011). SARAL/AltiKa (launched in 2013) was designed to have a smaller footprint and lower noise over all surfaces, due to the choice of antenna pattern, Kaband frequency and its lower altitude (Verron et al., 2015). CryoSat-2 (launched in 2010) is primarily a cryosphere mission and not planned for ocean observations. Yet over the last years, considerable efforts have been made by the ESA SAMOSA project (Ray et al., 2015) and the CNES Cryosat2 Processing Prototype (CPP) project (Boy et al., 2017) in collaboration with oceanographers to improve the waveform retracking over the ocean and provide adequate corrections for ocean observations. CryoSat-2 is in low-resolution mode over most of the global ocean but has synthetic aperture radar (SAR) mode observations available over a few regions, including the Mediterranean Sea, with improved along-track sampling down to $300 \mathrm{~m}$ and reduced noise. However, certain ocean corrections are less accurate than on Jason-2 or SARAL, including the radiometer correction and the mean sea surface estimate, since CryoSat- 2 is on a geodetic orbit. These three altimeter missions with different technologies and data processing will provide an ideal data set to test the improved observational capabilities in the NW Mediterranean Sea.

Previous studies have analysed the altimetric capabilities in the NW Mediterranean Sea from conventional along-track data (Bouffard et al., 2008, 2011; Birol and Delebecque, 2014; Birol and Nino, 2015), including using seasonal averaging to reduce the noise for Jason but maintaining alongtrack resolution (Birol et al., 2010). Here we will take a different approach, in order to measure the altimetric signalto-noise ratio statistically in the different seasons. We will calculate along-track sea level anomaly (SLA) spectra (e.g. $\mathrm{Fu}, 1983$ ), which allows us to observe the SLA spectral energy at different wavelengths, and also the time-averaged spectral noise at small wavelengths. In terms of signal, the spectral energy of SLA is higher at longer wavelengths, and lower at small wavelengths, and geostrophic turbulence theory involves a cascade of energy from the larger to smaller scales, leading to a steep spectral slope in wavenumber space. When spectra are averaged (over different ground tracks in a region and/or over time along the same ground track), the random altimeter noise averages out to create a flat spectral noise floor in the $1 \mathrm{~Hz}$ data. This spectral noise level then defines our altimeter noise. The intersection of this noise floor with the spectral slope will define the limit of the observable wavelengths, where the signal-to-noise ratio is statistically greater than 1.

Following $\mathrm{Xu}$ and $\mathrm{Fu}$ (2012) we will remove the spectral noise from the spectra before calculating the spectral slope, to improve the slope estimate and have more precise observational limits. This technique has been applied to the global altimeter data sets, for Jason-1 by $\mathrm{Xu}$ and $\mathrm{Fu}$ (2012) and for Jason-2, SARAL and CryoSat-2 by Dufau et al. (2016). Their results showed considerable geographical variations in the spectral slope, noise levels and mesoscale resolution $(\mathrm{Xu}$ and $\mathrm{Fu}, 2012$ ), and strong seasonal variations in the noise level and the mesoscale observing capabilities (Dufau et al., 2016). Neither study included the smaller Mediterranean Sea region, due to the limited spatial coverage in this regional sea. In our analysis, we will concentrate on tracks having at least $200 \mathrm{~km}$ length.

These studies calculated their spectral slopes over a fixed "mesoscale" band from 70 to $250 \mathrm{~km}$ wavelength. The Mediterranean Sea, which is dominated by smaller dynam- 
Table 1. Altimetric data used in this study.

\begin{tabular}{|c|c|c|c|c|}
\hline $\begin{array}{l}\text { Altimetric } \\
\text { mission }\end{array}$ & $\begin{array}{l}\text { Frequency } \\
\text { band }\end{array}$ & $\begin{array}{l}\text { High-frequency rate } \\
\text { (average } 1 \mathrm{~Hz})^{1}\end{array}$ & $\begin{array}{l}\text { Time period } \\
\text { used }\end{array}$ & $\begin{array}{l}\text { No. sections used in spectral } \\
\text { averaged mean (seasonal) }\end{array}$ \\
\hline Jason-2 & $\mathrm{Ku}$ & $20 \mathrm{~Hz}-\mathrm{LRM}$ & Jul 2008-Feb 2015 & 246 (summer: 65 , winter: 58 , spring: 71 , autumn: 52 ) \\
\hline SARAL & $\mathrm{Ka}$ & $40 \mathrm{~Hz}-\mathrm{LRM}$ & Mar 2013-Jan 2015 & 292 (summer: 66, winter: 66, spring: 96 , autumn: 64 ) \\
\hline CryoSat-2 & $\mathrm{Ku}$ & $20 \mathrm{hZ}-\mathrm{SAR}$ & Apr 2013-Apr 2014 & 276 (summer: 77 , winter: 69 , spring: 75 , autumn: 55 ) \\
\hline
\end{tabular}

LRM: conventional low-resolution mode; SAR: synthetic aperture radar mode.

First number corresponds to the total number of $200 \mathrm{~km}$ sections used in the regionally averaged spectra (Fig. 3); numbers in brackets correspond to the number of sections used in each seasonal average (Fig. 4).

ical structures, may have different spectral energy and spectral slopes in this band compared to open-ocean regions. The surface sea-state conditions are also dominated by short wind waves and less by long swell, which may impact on the radar altimeter's noise level. Both of these features will be considered in the first section of this paper. We aim to investigate the noise levels for the most recent altimeter missions, estimated from their spectral noise level in the Mediterranean Sea. We will revisit the appropriate filtering to be applied to remove the noise in different seasons. We will then consider what scales of ocean dynamics can be observed today in the Mediterranean Sea with along-track altimetry and investigate how much of the seasonal dynamical signal is observable above the seasonal noise.

In the second part of this paper, we will use a complementary approach and focus on the observation of individual features using a combination of altimetry and a limited number of glider sections and 2 years of high-frequency (HF) radar observations filtered at similar scales. We will examine whether the ocean scales observable with altimetry are also captured by the co-located in situ data. Glider-altimetry comparisons have been used for previous altimetry missions in the NW Mediterranean Sea (e.g. Bouffard et al., 2010) but not for the three most recent missions. For the glider comparison, we only have a limited number of historical co-located sections, and so gliders were deployed specifically along altimetric tracks for each of the three missions, under different mesoscale conditions. For the HF radar, we will use a HF radar site near Toulon, as part of the MOOSE observational array (Quentin et al., 2013), with an offshore extent of 25$75 \mathrm{~km}$ from the coast. We will discuss the strengths and limits of the different measurement systems' observation in the coastal band.

\section{Data sets used}

\subsection{Altimeter data}

Along-track SSH observations from the most recent altimetry missions (Jason-2, CryoSat-2 and SARAL/AltiKa) are analysed over the NW Mediterranean Sea (Fig. 1) and over different periods (Table 1). The data are made available from AVISO/CNES. Jason-2 is a conventional pulse-width limited

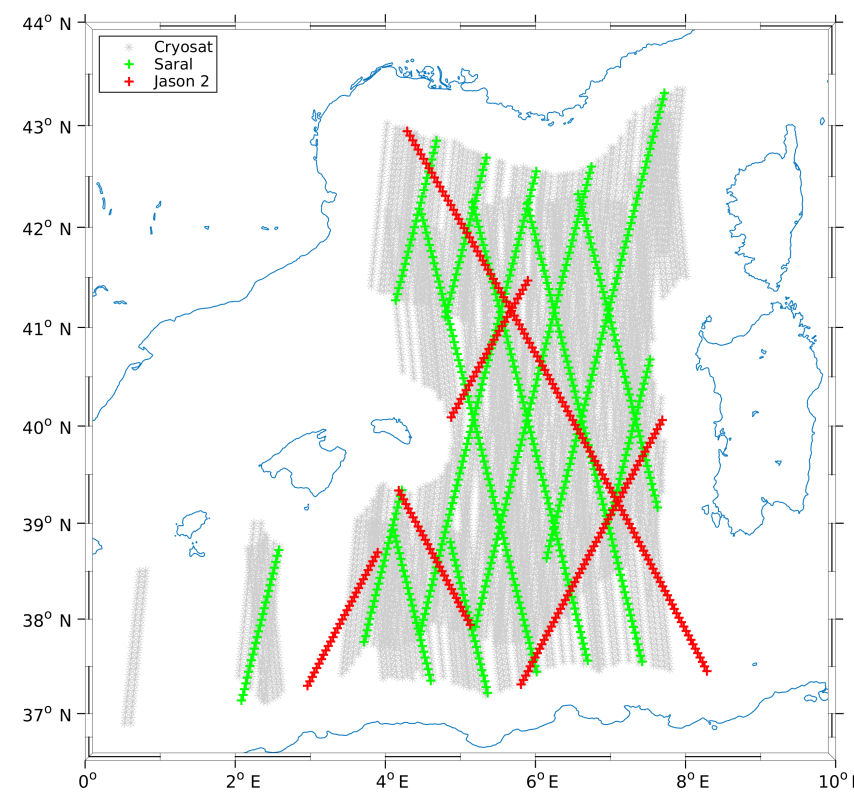

Figure 1. Distribution of altimeter tracks in the NW Mediterranean Sea showing the different missions: the 10-day repeat Jason-2 mission in red, 35-day repeat SARAL/AltiKa in green, and the 380-day repeat CryoSat-2 in grey. Only sections greater than $200 \mathrm{~km}$ are included in the spectral analysis, and only data more than $50 \mathrm{~km}$ from the coast are analysed to remove the increased errors in the coastal zone. The distance from the coast is calculated using the Stumpf database (http://oceancolor.gsfc.nasa.gov/DOCS/DistFromCoast).

altimeter operating in Ku-band (Lambin et al., 2010) and provides the longest time series: we use data over the 6.8-year period from July 2008 to February 2015. SARAL/AltiKa, with its $40 \mathrm{~Hz}$ Ka-band emitting frequency, its wider bandwidth, lower orbit, increased pulse repetitivity frequency and reduced antenna beamwidth, provides a smaller footprint and lower noise than the Ku-band altimeters (Verron et al., 2015). We use data from the nearly 2-year period from March 2013 to January 2015. CryoSat-2 is a synthetic interferometric altimeter (SIRAL) Ku-band instrument operating in three modes (low-resolution mode (LRM), synthetic aperture radar mode (SARM) and SAR interferometric mode). Only the SARM data are available over the Mediterranean Sea, and we use data from the CNES CryoSat-2 processing prototype 
(version 14) from CNES (Boy et al., 2017) over the 1-year period April 2013 to April 2014. For all three missions we will analyse the $1 \mathrm{~Hz}$ data only, which have a flat noise floor. Higher-frequency data $(20$ or $40 \mathrm{~Hz}$ ) show a spectral bump at wavelengths less than $70 \mathrm{~km}$, which does not allow us to estimate a stable noise floor (Dibarboure et al., 2011).

The choice to analyse different periods was dictated by the data availability and our desire to have longest possible time periods available for the seasonal analyses. The limited quantity of altimeter cycles considered during this period is compensated by the spatial averaging of available tracks in the NW Mediterranean Sea, which improves the statistical significance of our analysis.

Along-track SSH observations are maintained at their original observational position and corrected for all instrumental, environmental and geophysical corrections. Only the time variable part of the SSH is considered following Stammer (1997), Le Traon et al. (2008) and Xu and $\mathrm{Fu}(2011,2012)$. SLAs are calculated for all missions relative to their precise along-track mean sea surface for Jason-2 and SARAL, both on a long-term repeat track. CryoSat is on a geodetic orbit, and its SLAs are calculated relative to a gridded mean sea surface (MSS_CLS2011, http://www.aviso.altimetry.fr/en/data/ products/auxiliary-products/mss.html), which can introduce slightly higher errors over scales of $40-80 \mathrm{~km}$ wavelength (Dibarboure et al., 2011; Dufau et al., 2016). In the following analyses of spectra and geostrophic current anomalies, we will use the time-varying SLAs.

\subsection{Glider data}

A large number of gliders have been deployed in the NW Mediterranean Sea as part of the MOOSE project (http: //www.moose-network.fr/gliders), with more than a hundred glider sections available in the region during the 6.5 years of our study. However, since our objective was to validate the smaller-scale structures that move rapidly, it was important that the glider and altimeter observations were colocated in space and time. Two glider sections were available along a Jason-2 track in September-October 2012. MOOSE and CNES also co-funded the deployment of gliders along three SARAL tracks as part of the Comsom campaign in October-November 2014, and along two CryoSat-2 tracks and three SARAL tracks in April-May 2015 (see Fig. 5a and Table 2).

Slocum gliders were used, diving at a $26^{\circ}$ inclination with an average horizontal speed of around $0.35 \mathrm{~m} \mathrm{~s}^{-1}$. They reach a maximum depth of $1000 \mathrm{~m}$, and the distance between two surface positions is around $2-3 \mathrm{~km}$. The deployments are made away from the coast to be in deep water, although an onboard captor can detect whether they approach the bottom before $980 \mathrm{~m}$. The gliders were deployed a few days before the passage of the satellite in order to be sampling along the track when the altimeter passed. The altimeter passes every
10 days for Jason, and every 35 days for SARAL and in a given region every month for CryoSat-2. So with this type of precise-date deployment, there is no guarantee that the glider and altimeter pass will cross an energetic structure at the time and position that the altimeter passes.

For comparison with the altimeter data, we need to obtain steric heights from the glider relative to $1000 \mathrm{~m}$. For this, we calculate a single vertical profile at the central position for each of the diagonal dives (descending or ascending) and calculate steric heights from the density anomalies. Geostrophic velocities are also calculated relative to the $1000 \mathrm{~m}$ depth.

There is an additional "drift" speed that can be added to this geostrophic velocity, associated with the lateral heading correction used to keep the glider on track against a strong current. This drift correction represents the total current over the upper $1000 \mathrm{~m}$ and will include the barotropic currents close to the continental slope, some ageostrophic surface currents and correction for the upper baroclinic flow. This correction was generally small in our region except near the continental slope, and we will clearly identify when this correction is used in the following study.

\subsection{HF radar data}

As part of the MOOSE observing system, a HF radar system has been installed near Toulon (http://hfradar.univ-tln. fr/HFRADAR) to monitor the Northern Current, with gridded data available since 2012 . HF radars measure the reflected radar signal from the ocean surface at a given lateral incidence angle. The surface currents are obtained after subtracting the surface wave speed, which is estimated from the measured frequency of the wave energy peak and the known frequency of the emitted radar signal. Two radars orientated with different angles allow the determination of the current direction.

The Toulon HF radar system uses two WERA radars that provide surface current vectors over a region extending 80$100 \mathrm{~km}$ offshore, with a spatial resolution of $3 \mathrm{~km}$ and an angular resolution of $2^{\circ}$. They operate at $16-17 \mathrm{Mhz}$. Observations are collected every $20 \mathrm{~min}$ and data have been edited and averaged daily over the period May 2012September 2014. The surface current vectors represent the total current averaged over the upper $1 \mathrm{~m}$ of the ocean and include a significant ageostrophic component, not present in the altimetric currents.

\section{Spectral analysis of along-track altimeter data}

Spectral analyses are performed on each of the three altimeter missions, with their tracks shown in Fig. 1. Only data more than $50 \mathrm{~km}$ from the coast are analysed to avoid the increased errors in the coastal zone. Each track and cycle is then selected along a common segment of $200 \mathrm{~km}$. This segment length was chosen to allow a large number of altimeter 
Table 2. Characteristics of the co-located glider and altimeter track sections.

\begin{tabular}{lrlllrr}
\hline $\begin{array}{l}\text { Altimeter } \\
\text { track }\end{array}$ & $\begin{array}{r}\text { Along-track } \\
\text { filtering }\end{array}$ & $\begin{array}{l}\text { Glider } \\
\text { name }\end{array}$ & $\begin{array}{l}\text { Start date } \\
\text { of section }\end{array}$ & $\begin{array}{l}\text { End date } \\
\text { of section }\end{array}$ & $\begin{array}{r}\text { Section } \\
\text { length }(\mathrm{km})\end{array}$ & $\begin{array}{r}\text { No. glider } \\
\text { profiles }^{2}\end{array}$ \\
\hline Jason 146 & 50 & Campe & 23 Sep 2012 & 8 Oct 2012 & 292 & 111 \\
Jason 146 & 50 & Campe & 8 Oct 2012 & 23 Oct 2012 & 327 & 80 \\
SARAL 846 & $\mathbf{3 5}$ & Eudoxus & 23 Oct 2014 & 29 Oct 2014 & 125 & 54 \\
SARAL 57 & $\mathbf{3 5}$ & Milou & 27 Oct 2014 & 3 Nov 2014 & 164 & 92 \\
SARAL 388 & $\mathbf{3 0}$ & Milou & 9 Nov 2014 & 13 Nov 2014 & 77 & 55 \\
SARAL 973 & 35 & Bonplan & 13 Apr 2015 & 22 Apr 2015 & 180 & 101 \\
SARAL 973 & 35 & Tintin & 17 Apr 2015 & 23 Apr 2015 & 115 & 58 \\
SARAL 973 & 35 & Tintin & 8 May 2015 & 13 May 2015 & 99 & 56 \\
CryoSat 493 & 35 & Bonplan & 24 Apr 2015 & 1 May 2015 & 166 & 101 \\
CryoSat 493 & 35 & Tintin & 25 Apr 2015 & 4 May 2015 & 188 & 101 \\
\hline
\end{tabular}

1 Altimetric data are filtered with a Loess filter at different wavelength cutoffs depending on the mission and season (see text).

2 All glider data are filtered with a two-step Butterworth filter which removes high-frequency signals $<30 \mathrm{~km}$ wavelength.

segments in different regions in between the numerous islands and to be more than $50 \mathrm{~km}$ from the coast, to avoid the increased errors in the coastal altimeter data. This segment length is also long enough to well resolve the dominant scales (Rossby radius of 5-15 km). Missing data are a problem for a stable spectral analysis. If fewer than three consecutive $1 \mathrm{~Hz}$ points are missing $(20 \mathrm{~km})$, the data are linearly interpolated; if a larger gap is present the cycle is eliminated from the analysis. Tracks passing over large islands are thus eliminated (see Fig. 1). Wavenumber spectral analysis is then performed by Fourier transform on the ensemble of the remaining segments for each mission (see Table 1). The cycles are averaged in wavenumber space for the entire period and for each season.

An example of the power spectral density (PSD) of SLA averaged for all of the Jason-2 data in the NW Mediterranean Sea over the period 2008-2015 is shown as the black curve in Fig. 2. The PSD is high at longer wavelengths $(>300 \mathrm{~km})$. There is a cascade of energy over the mesoscale range from 50 to $300 \mathrm{~km}$, but the spectra become whiter at small wavelengths (i.e. less than $50 \mathrm{~km}$ ), where the weaker ocean energy is hidden by the stronger instrument and geophysical noise.

In the following seasonal analyses, the noise level will be calculated as a constant PSD value estimated between 12 and $25 \mathrm{~km}$ wavelength, as in Dufau et al. (2016) (e.g. black horizontal dashed line, Fig. 2).

Following the global studies made by $\mathrm{Xu}$ and Fu (2012) and Dufau et al. (2016), we then subtract this statistically stable noise level from the mean spectral curve, to obtain an unbiased spectral estimate corrected for the noise (red solid line curve, Fig. 2). The spectral slope of this unbiased estimate is steeper over the mesoscale range and corresponds to a $k^{-2.5}$ slope and the SLA PSD cascade continues more smoothly down to smaller wavelengths.

We define the mesoscale observability limit as the wavelength corresponding to the intersection of the spectral slope and the noise level, where the signal-to-noise ratio is greater

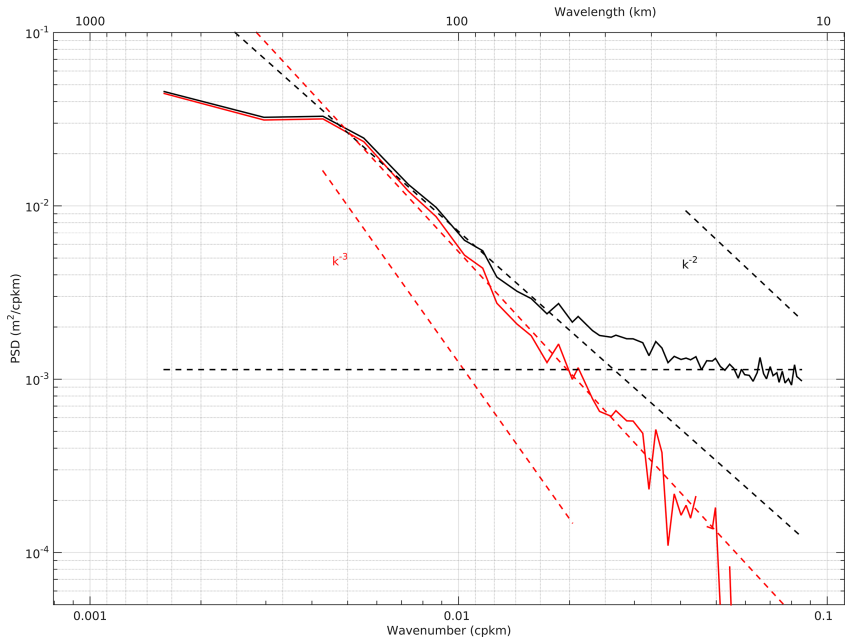

Figure 2. Mean wavenumber spectra (power spectral density) for Jason-2 sea level anomalies, averaged over all tracks in the NW Mediterranean Sea $>50 \mathrm{~km}$ from the coast (black curve) for the period 2008 to 2015 . The estimated noise level is shown as the horizontal black dashed line. The unbiased spectra (red curve) are obtained by subtracting this constant noise from the original spectra. The spectral slope (red dashed line) is calculated between 50 and $200 \mathrm{~km}$ wavelength. The intersection between these two curves occurs around $50 \mathrm{~km}$ wavelength for this case, which represents the mesoscale observational limit, above which the mean signalto-noise ratio is $>1$.

than 1 . This is a statistical representation of the average ocean and noise conditions over the entire period and over the entire region analysed. In some local cases, smaller energetic structures may still be observable above the altimetric noise. However in the following results, we will discuss this regional statistical approach.

The mean spectra for the three altimeter missions over the NW Mediterranean Sea are shown in Fig. 3a for the $200 \mathrm{~km}$ segment tracks in Fig. 1 and over the 13-month common 

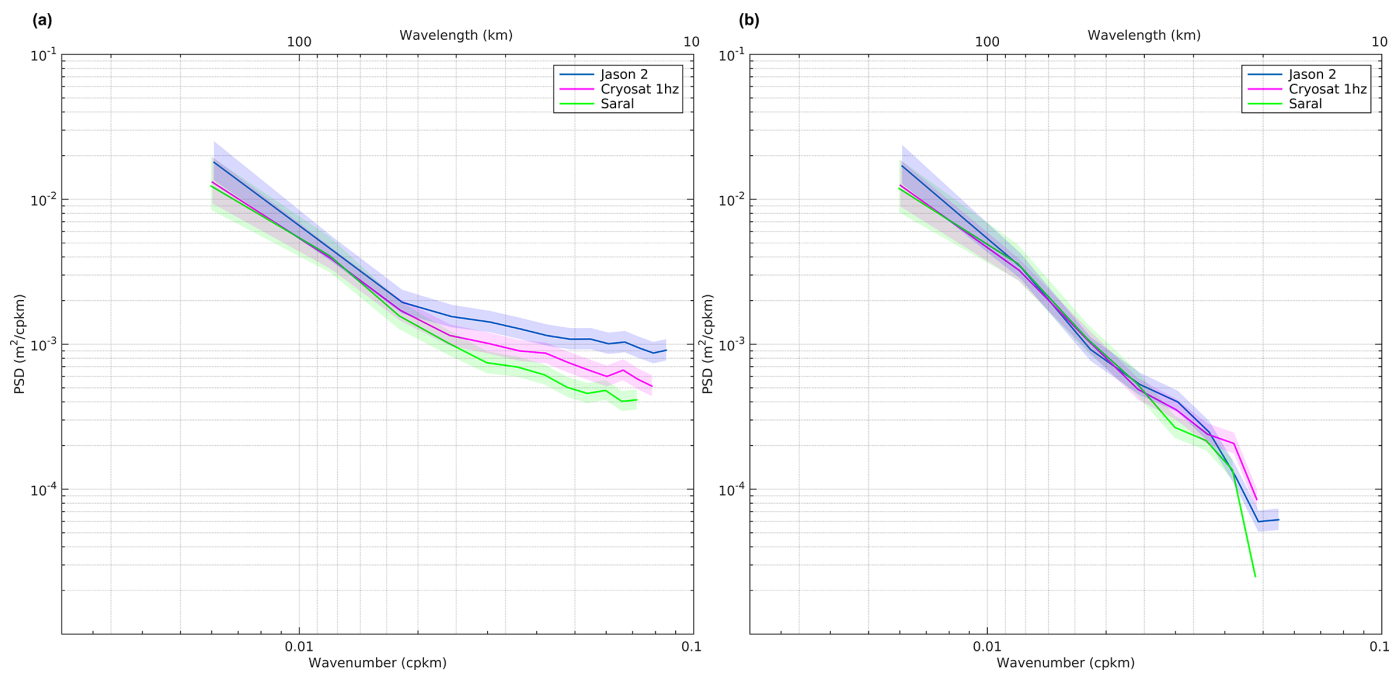

Figure 3. (a) Mean wavenumber spectra (power spectral density) for the three altimeter missions, averaged over the $200 \mathrm{~km}$ track segments in the NW Mediterranean Sea, >50 km from the coast, and for the common period 1 April 2013-30 April 2014. Jason-2 is in blue, SARAL in green, CryoSat-2 SAR $1 \mathrm{~Hz}$ data in pink. (b) The unbiased spectra with a constant noise level removed, resulting in a mean $k^{-2.5}$ spectral slope. Shading represents the error bars, based on a chi-squared test with the number of degrees of freedom being wavenumber dependent. Table 1 gives the number of sections used.

data period from 1 April 2013 to 30 April 2014. The unbiased estimate with the noise removed is in Fig. 3b. Recall that the space-time samplings of the three missions are different, and as such they may capture different dynamics at different regions. So we do not expect the spectra to be perfectly aligned. More distinctive are the different noise levels between 15 and $100 \mathrm{~km}$ wavelength. Jason-2 has the highest noise level in this region, followed by CryoSat-2 in SAR mode. SARAL/AltiKa in Ka-band exhibits the lowest noise of all.

When a constant noise level is removed from each spectral PSD, the spectral slopes line up surprisingly well, given the different space-time sampling of the three missions over this 13-month period. The spectral slope is again around $k^{-2.5}$ from a fit to the unbiased spectra over the wavelength range from 50 to $200 \mathrm{~km}$. These spectral slopes in the offshore regions of the Mediterranean Sea are quite shallow compared to the $k^{-5}$ slopes expected for quasi-geostrophic theory (Stammer, 1997). The reason for this needs further investigation, but smaller slopes are also characteristic of openocean low-eddy-energy regions (Xu and Fu, 2012). For the Mediterranean Sea, the dominant mesoscale energy at small Rossby radius scales tends to flatten the spectra, but internal waves or mean sea surface errors in the CryoSat-2 data could also contribute to higher SSH energy at small scales and flatter spectra (Dufau et al., 2016).

The fact that the CryoSat-2 $1 \mathrm{~Hz}$ data in SAR mode had a higher noise level than SARAL/AltiKa was unexpected. We verified that the CryoSat $-220 \mathrm{~Hz}$ data were consistent with the $1 \mathrm{~Hz}$ averages, so this is not an averaging problem. The CryoSat-2 $20 \mathrm{~Hz}$ SAR mode does exhibit a spec- tral hump for this region and time period that was not present in other regions with SAR data (Agulhas or tropical Pacific; S. Labroue, personal communication, 2016). This warrants further analysis of the particular surface roughness conditions occurring in the NW Mediterranean during this year, and further expertise in SAR processing for the Mediterranean conditions is needed. These results reinforce the very low noise level associated with the $40 \mathrm{~Hz}$ Ka-band SARAL data, averaged here to $1 \mathrm{~Hz}$.

Seasonal spectra were also calculated from the longest time series possible, i.e. over 6.5 years for Jason- 2 data, over 22 months for SARAL/AltiKa, and for the shorter 13-month period for CryoSat-2 (see Table 1). The spectral noise floor levels for the seasonal analyses are shown in Fig. 4a. Note the spectral units are in $\mathrm{m}^{2} \mathrm{cpkm}^{-1}$, where cpkm refers to cycles per km. Jason-2 and SARAL/AltiKa show a large seasonal variability in their noise levels, with highest noise levels in winter $\left(1.2 \times 10^{-3} \mathrm{~m}^{2} \mathrm{cpkm}^{-1}\right)$ and then autumn, due to the high sea-state roughness in these months from the stronger wind-wave conditions which increases the spectral SLA "hump" at wavelengths from 30 to $70 \mathrm{~km}$ (Dibarboure et al., 2014). In summer, the Jason-2 noise level is only $0.8 \times 10^{-3} \mathrm{~m}^{2} \mathrm{cpkm}^{-1}$, but this is still higher than the noise floor in any season for the SARAL or CryoSat-2 missions. SARAL with its small footprint has the lowest noise levels but has strong seasonal variability, with values ranging from a low $0.3 \times 10^{-3} \mathrm{~m}^{2} \mathrm{cpkm}^{-1}$ in summer to $0.7 \times 10^{-3} \mathrm{~m}^{2} \mathrm{cpkm}^{-1}$ in winter. The CryoSat-2 SAR mode shows very stable background noise levels over this 1 -year record, varying between 0.6 and $0.8 \times 10^{-3} \mathrm{~m}^{2} \mathrm{cpkm}^{-1}$. The reasons for this stable seasonal noise level are not yet known. 
(a)

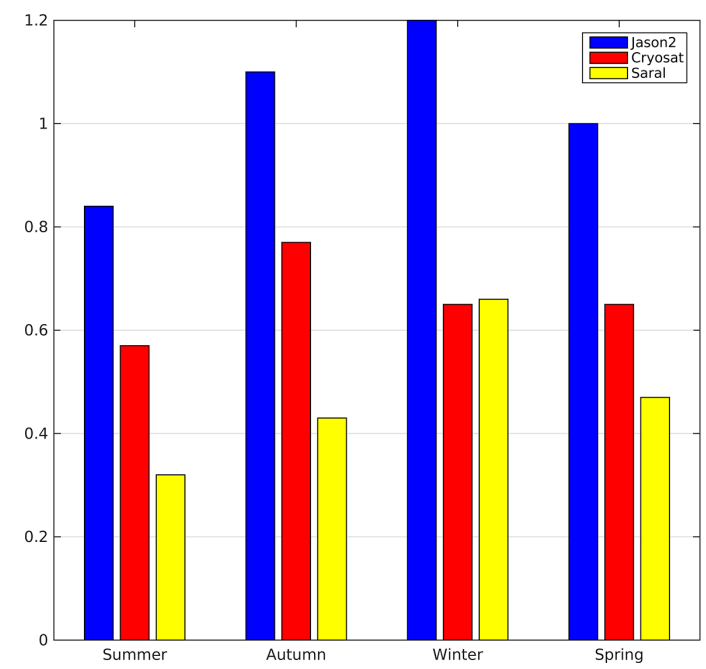

(b)

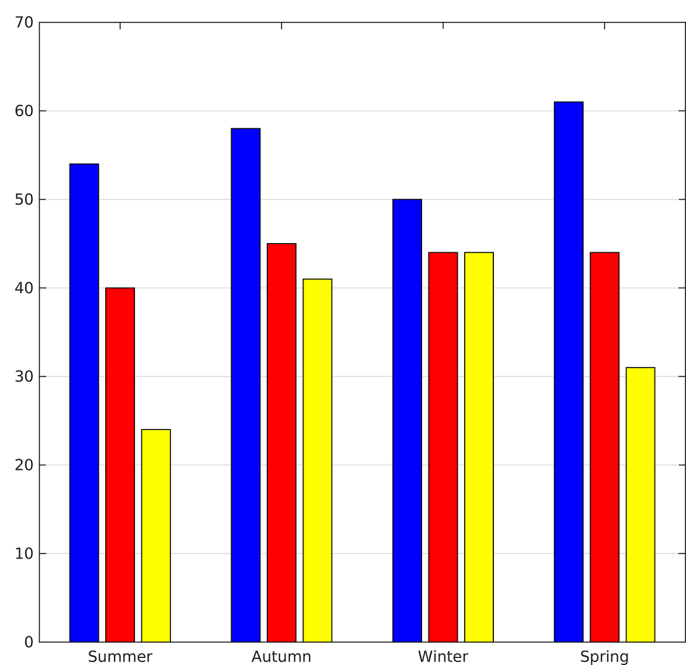

Figure 4. (a) Seasonal noise levels (in $10^{-3} \mathrm{~m}^{2} \mathrm{cpkm}^{-1}$ ) for Jason-2 (blue), CryoSat-2 SAR mode (orange) and SARAL/AltiKa (yellow) derived from along-track wavenumber spectra. (b) Seasonal observational limits in terms of wavelength (in $\mathrm{km}$ ) where the signal-to-noise ratio is $>1$ for each altimeter mission. Table 1 gives the number of sections used.

However CryoSat-2 has a long repeat cycle (369 days), so different geographical regions are sampled in different seasons; there may be strong interannual variations in the wind-wave conditions that merit more detailed investigation. The additional mean SSH errors introduced due to the nonrepeating track will also impact the CryoSat-2 spectra over all seasons.

Figure $4 \mathrm{~b}$ shows the observational limits for each altimeter mission by season. Clearly, the background noise is not the only limiting factor on the scales of mesoscale energy that we can observe. The SLA energy at low wavelengths also varies from one season to another. In winter, when the mixed layers are deepest and energetic deep convection cells occur in the NW Mediterranean Sea (e.g. Herrmann et al., 2008), all of the altimeter missions can observe wavelengths down to $40-50 \mathrm{~km}$ (individual features of 20-25 km). In summer when the submesoscales are weaker, SARAL can detect ocean scales down to $35 \mathrm{~km}$ wavelength, whereas the higher noise from Jason-2 and CryoSat-2 blocks the observation of scales less than $50-55 \mathrm{~km}$. This characteristic was also noted in the global analysis of Dufau et al. (2016). Unfortunately in winter, when we would like to observe the smaller energetic submesoscales, all of the radar altimeters observe higher noise levels associated with the higher windwave field.

\section{Co-located altimeter and glider observations}

The previous section highlighted that the altimetric noise was effectively masking the smaller-scale SLA signals in the along-track data. The smallest scales observable with a signal-to-noise ratio greater than 1 will vary from one altime- ter mission to another and seasonally. Statistically, we cannot observe structures less than $35-45 \mathrm{~km}$ wavelength with SARAL, or $50-60 \mathrm{~km}$ wavelength with the higher noise of Jason-2. However, individual energetic features may be revealed above the statistical noise. We will explore this with a series of co-located along-track altimeter-glider sections and compare the vertical structure observed by the gliders with their steric height and geostrophic velocities.

In this section, the filtering of the along-track altimetry data is based on the standard Loess filtering applied to the CTOH coastal processed data (Birol et al., 2010; Birol and Nino, 2015). For each glider-altimeter comparison, the first estimate of the along-track altimeter filtering scales was based on the seasonal spectral analysis results for each altimeter mission (see Sect. 3). Other cut-off frequencies around this seasonal statistical value were also tested. The filter which gave the best results in terms of glideraltimeter correlation coefficient and which had the lowest cut-off wavelength was then chosen. The altimeter filter values are given in Table 2.

One should bear in mind that the glider steric height and geostrophic velocities (with or without their surface drift adjustment) will observe different dynamics from the altimetric sea level and geostrophic velocity anomalies. The steric height calculated from gliders represents the upper ocean baroclinic component due to the density anomalies above $1000 \mathrm{~m}$ depth. Altimetric SLAs include the full-depth baroclinic motions and the barotropic component, and the barotropic flow may be quite active in the NW Mediterranean Sea, in particular near the shelf break and slope (F. Lyard, personal communication, 2016). When the glider "surface drift" is added to the glider geostrophic currents relative to 

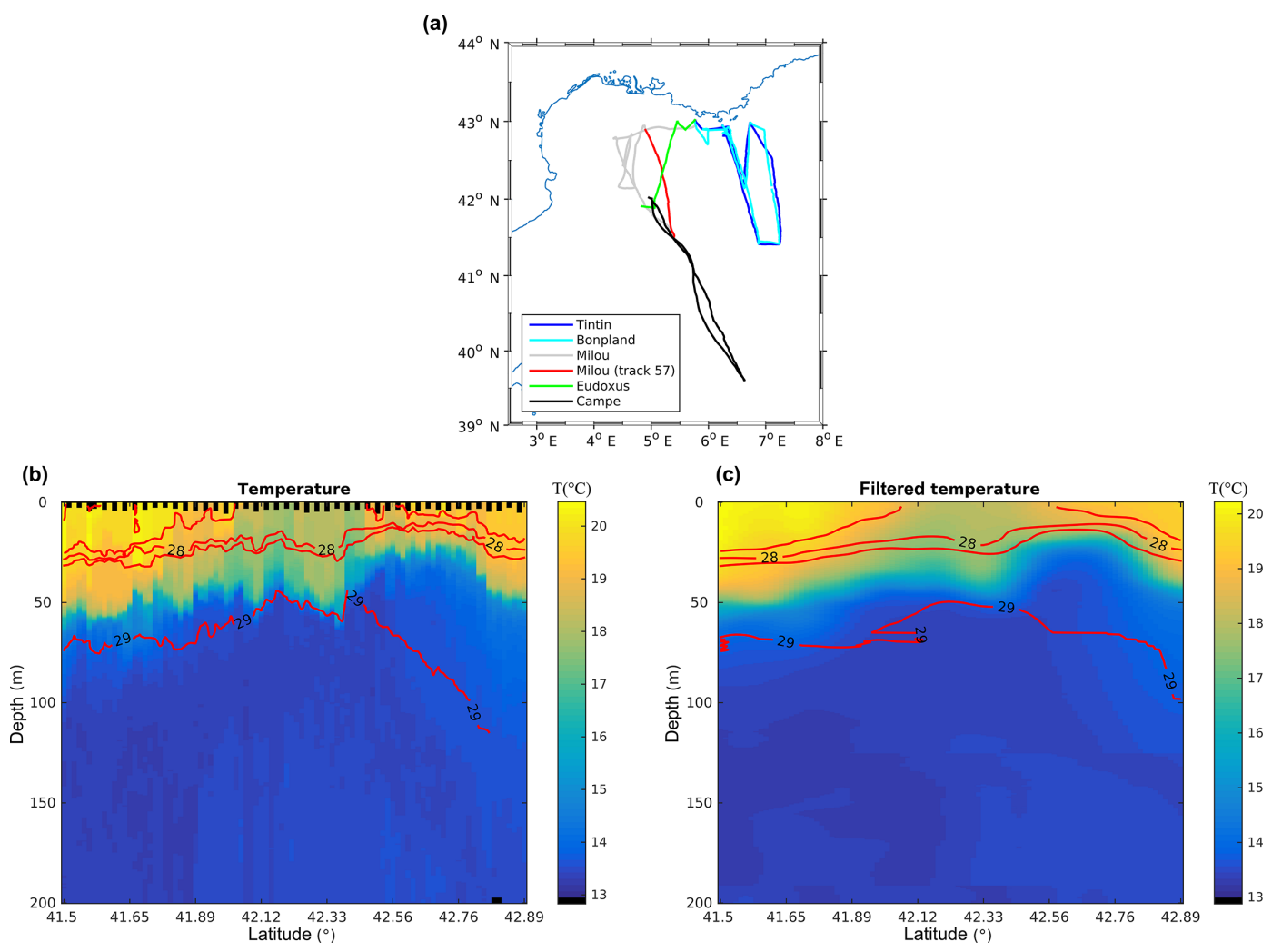

Figure 5. (a) Location of the different gliders used in this analysis. In red, the glider Milou section (155 km long) along the SARAL altimeter track 57 from 27 October to 3 November 2014. (b) Vertical temperature section from the Milou glider over the upper $200 \mathrm{~m}$. (c) Filtered temperature section with cutoff at $30 \mathrm{~km}$ wavelength.

$1000 \mathrm{~m}$, this may partially correct for the missing barotropic component. Altimetry may also include other SLA signals, such as from internal tides or internal waves, which contribute as errors in the geostrophic velocity calculation (although tides are small in the Mediterranean Sea). In addition, the altimetric SLAs have the mean ocean circulation removed, whereas the gliders provide the total upper ocean baroclinic flow. For consistency, the mean dynamic topography and mean geostrophic velocities derived from Rio et al. (2014) are added to the altimetric data for this comparison. The third main difference is the time taken to make a section over 100 to $300 \mathrm{~km}$. The altimeter makes a "snapshot" of the section as it passes at $7 \mathrm{~km} \mathrm{~s}^{-1}(200 \mathrm{~km}$ in $30 \mathrm{~s})$ whereas the glider moves at $0.35 \mathrm{~m} \mathrm{~s}^{-1}$ ( $200 \mathrm{~km}$ in 6.5 days). We will see that slow-moving structures may be well-sampled by both; rapidly evolving smaller-scale structures are harder to colocate.

One crucial point is that the gliders have their own noise and also measure HF ageostrophic ocean structures that will not be observable with altimetry. Figure 5 shows a vertical temperature section over the upper $200 \mathrm{~m}$ from the glider Milou along the SARAL altimeter track 57 from 27 October to 3 November 2014. Figure 5b shows the very small-scale signals in the upper ocean temperature structure along this
$164 \mathrm{~km}$ long section. These may be associated with noise in the glider heading or from the processing steps, or from internal waves or rapid submesoscale structures. To remove these scales, we have applied a recursive Butterworth second-order along-track filter to the density data, before calculating the steric height or geostrophic anomalies, with a filter cut-off at $30 \mathrm{~km}$ wavelength, designed to retain the typical Rossby radius scales of $10-15 \mathrm{~km}$ in the NW Mediterranean Sea. This filtering step was recommended from previous glider studies (e.g. Durand et al., 2016). An example of the filter applied to the same temperature section is shown in Fig. 5c. Similar filtering is applied to the different glider sections presented below.

Ten glider sections are available, co-located with altimeter tracks (details given in Table 2). Here we present three glider track sections along different altimeter mission tracks.

\subsection{Jason-2-glider comparison over a large slow eddy}

The glider Campe followed a Jason-2 track 146 over a $300 \mathrm{~km}$ section from 42 to $39.5^{\circ} \mathrm{N}$ over a 1 -month period 23 September-23 October 2012. During this period, Jason-2 passed three times over the same track. Jason-2 data were filtered using a Loess filter with a $50 \mathrm{~km}$ cutoff for this summer-autumn section (Table 2). Figure 6a shows the 
(a)

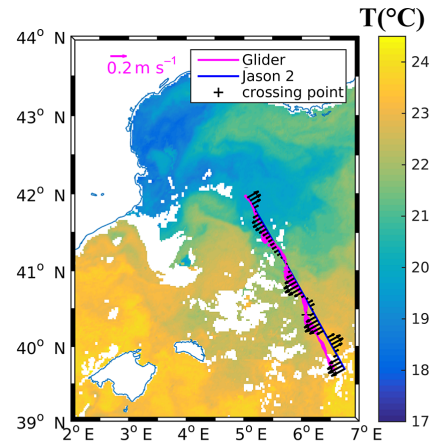

(c)

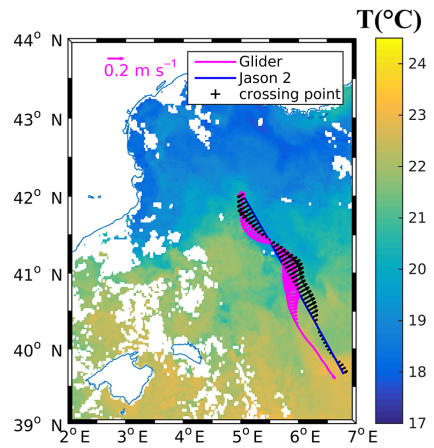

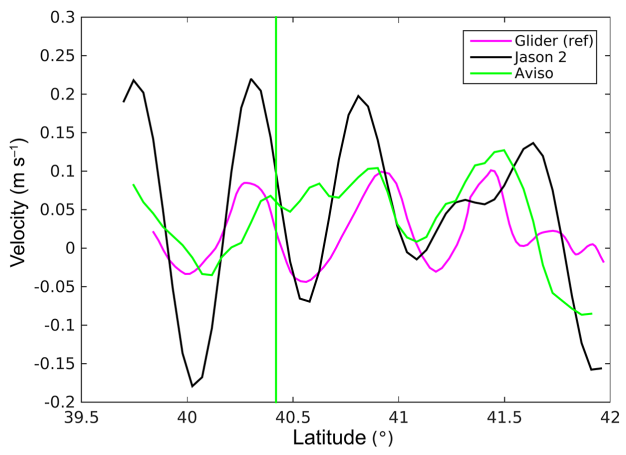

(d)

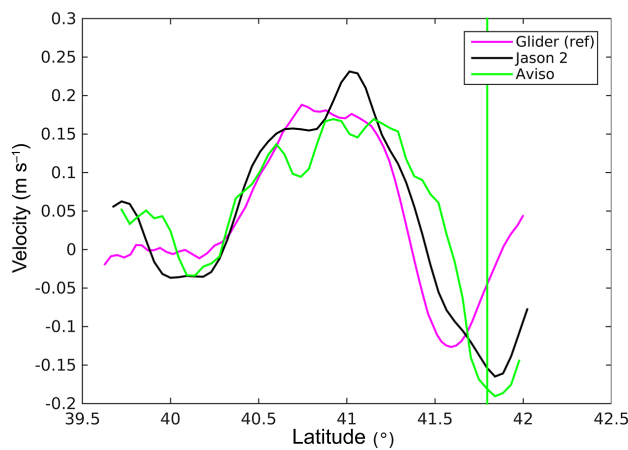

Figure 6. (a) Co-located Jason-2 track and currents (in black) and glider track and currents (in pink) for the southbound leg, overlaid with a satellite SST plot on 1 October 2012. (b) Along-track comparison of geostrophic velocities for the glider (including the drift velocities) in pink, and filtered along-track Jason-2 data in black. Mapped AVISO altimeter data, interpolated back onto the Jason-2 track, are in green. Green vertical line shows the position when the Jason-2 data and gliders are co-located in time. (c)-(d) Same but for the northbound section with SST fields from 21 October 2012; 48h SST fields at $0.02^{\circ}$ resolution from CLS.

glider cross-track geostrophic currents (in pink) with the Jason-2 cross-track currents superimposed (black) for the southward passage on 1 October 2012, overlaid on the satellite SST for the same date. The northward passage centred on 21 October 2012 is in Fig. 6c. The southbound section in late September has weak currents and is located slightly to the west; the northbound section crosses a strong mesoscale structure with an eastward current from 40.3 to $41.3^{\circ} \mathrm{N}$, then a westward return current from 41.3 to $42^{\circ} \mathrm{N}$ at the northern end, when the third Jason pass is co-located. The filtered glider data and the filtered Jason data are also shown for the southbound section (Fig. 6b) and the northbound section (Fig. 6d). The instant of the Jason-2 passage is marked by a vertical line -identifying the latitude where the glider and the Jason observations coincide exactly in time. The geostrophic currents from the AVISO 2-D maps are also shown for reference.

The southbound section crosses a series of small reversing currents around small SST structures of 30-50 km (Fig. 6a). The glider and along-track Jason-2 data show cross-track currents in phase, although the Jason-2 amplitudes are stronger (correlation, $r=0.5$; RMSE $=0.06 \mathrm{~m} \mathrm{~s}^{-1}$ ). This may be real (due to deeper baroclinic or barotropic structures not observed by the glider's upper $1 \mathrm{~km}$ observations) or in- duced by the effects of filtering higher noise. The mapped AVISO data have similar amplitude to the glider data but are not in phase, which reduced their statistical correlation $\left(r=0.4 ; \mathrm{RMSE}=0.06 \mathrm{~m} \mathrm{~s}^{-1}\right)$. Adding the glider "drift" reference currents introduces little change to these results.

Three weeks later, the northbound section crosses a strong mesoscale eddy. The three data sets present similar eastward currents across the mesoscale eddy, and although the amplitude of the westward current near $42^{\circ} \mathrm{N}$ is similar, along-track altimetry positions the return flow $30 \mathrm{~km}$ further north than is detected by the glider. For this larger eddy, $100 \mathrm{~km}$ in diameter, the AVISO 2-D maps and the $50 \mathrm{~km}$ filtered along-track data both provide a good estimate of the glider's geostrophic currents $(r=0.9)$ with similar RMSE ( $\sim 0.07 \mathrm{~m} \mathrm{~s}^{-1}$ for both data sets).

\subsection{SARAL-glider comparison over a small rapid meander}

Although a number of satellite underpasses were planned for SARAL, different deployment problems limited the number of successful intercomparisons (bad weather, gliders leaking, errors in estimating the satellite position, etc.). The longer sections did not necessarily cross any energetic features, and we eliminated sections where the currents were very weak. 
(a)

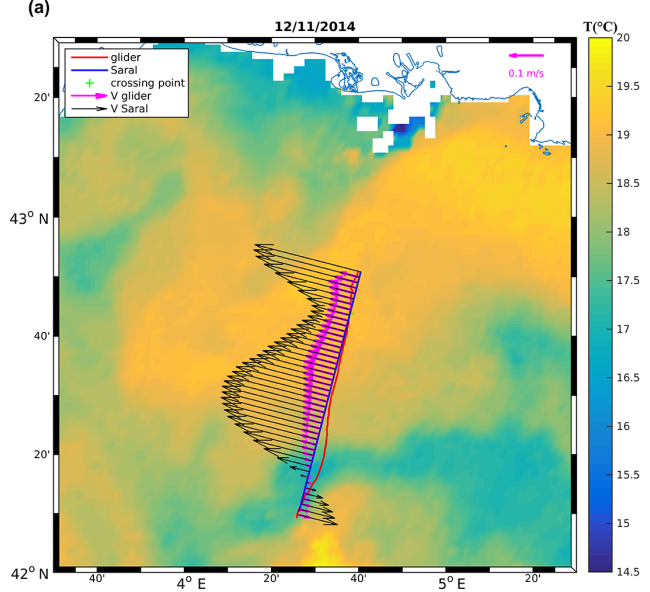

(b)

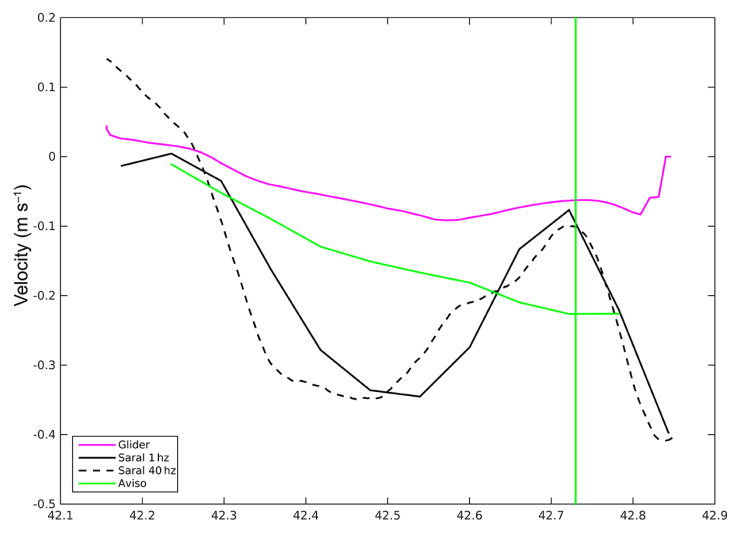

Figure 7. (a) Co-located SARAL track 388 and currents (in black) and glider track and currents (in pink), overlaid with a satellite SST plot on 12 November 2014. (b) Along-track comparison of geostrophic velocities for the glider (including the drift velocities) in pink, and filtered SARAL data in black. Mapped AVISO altimeter data, interpolated back onto the altimeter track, are in green. Green vertical line shows the position when the altimeter data and gliders are co-located. Daily SST fields at $0.02^{\circ}$ resolution from CLS.
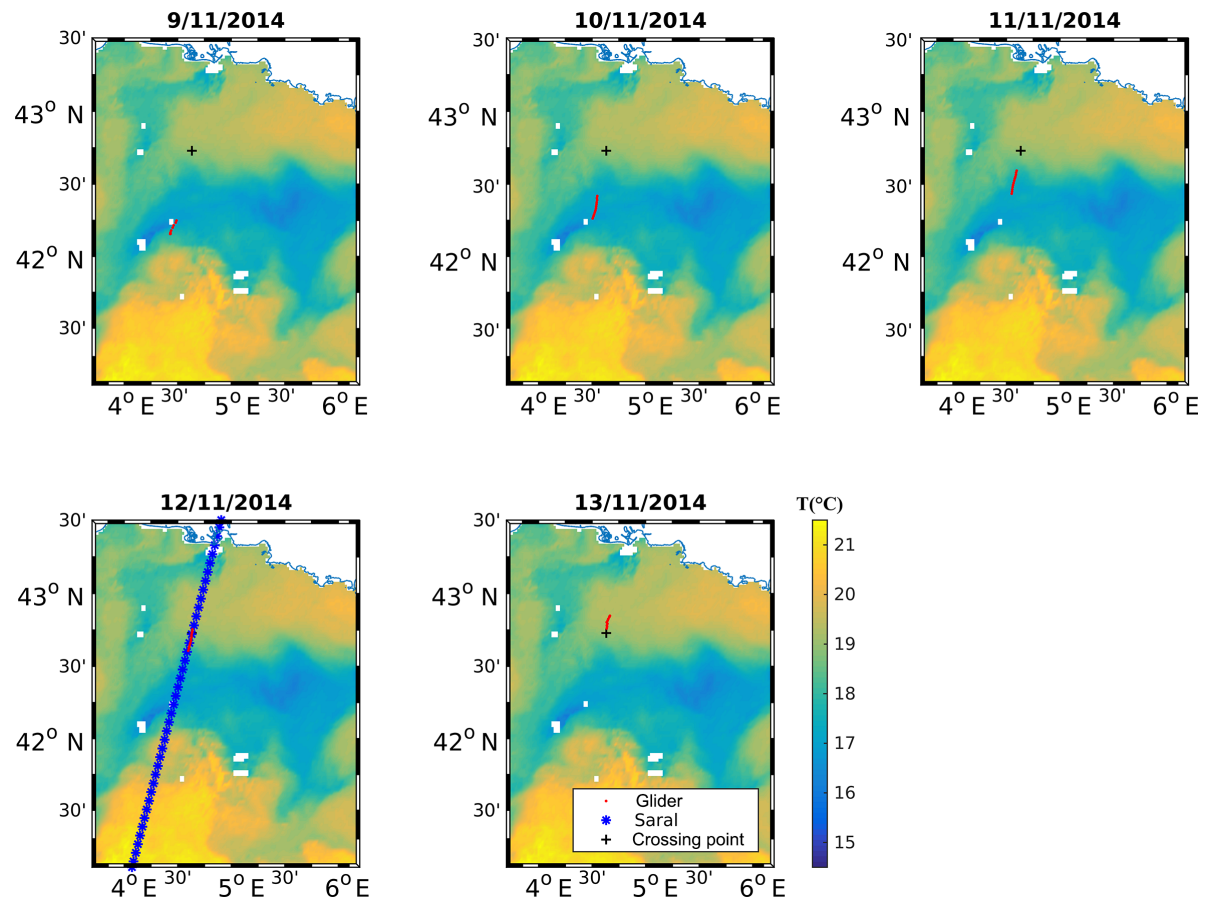

Figure 8. Five-day series of satellite SST maps for the period 9-13 November. The glider position is shown each day (in red), the SARALglider crossing position on 12 November (in black), and the SARAL track passing on 12 November 2014 . Daily SST fields at $0.02^{\circ}$ resolution from CLS.

The short section presented here highlights another difficulty - comparing small-scale structures in a rapidly evolving field.

Figure 7a shows an example of the SARAL-glider comparison for the SARAL track 388 and the glider Milou, which crossed a narrow, intense, westward current around $42.75^{\circ} \mathrm{N}$, a broad, weak, westward current further south, and then touched an eastward return flow around $42.25^{\circ} \mathrm{N}$. These nar- row currents are the limit of the observability with the gliders, given the filtering cutoff at $30 \mathrm{~km}$ wavelength. In comparison, the altimeter data show a broad intense westward flow over the entire section, except for the return eastward flow in the south. The along-track comparison of their amplitudes (Fig. 7b) shows that the two systems measure similar currents at the exact time of the SARAL passage (vertical line), but otherwise the broad, intense westward flow cap- 
tured by altimetry is not observed by the gliders. The mapped AVISO data are halfway between.

If the glider and altimeter observations are overlaid on a daily time series of satellite SST maps, the differences between these two observations becomes clearer. Figure 8 shows the 5 days needed by the glider to complete this $77 \mathrm{~km}$ section to $1000 \mathrm{~m}$ depth and the evolving SST conditions during this period. On the 9 November 2014, the glider was in the south and crossed a cold eastward-moving filament. On 10 November, the glider is in weaker conditions. On 11 November, the warmer westward-flowing current starts to shift southward and on 12 November, when Jason-2 passed over, the warm branch has extended south to $42.3^{\circ} \mathrm{N}$.

This example highlights the difficulty in comparing sections constructed from 5 days of glider data with the nearinstantaneous coverage from the along-track altimetry data. These small-scale structures less than $50 \mathrm{~km}$ evolve quickly, and having observations that are not exactly co-located in space and time leads to large differences.

\subsection{CryoSat-2-glider comparisons}

The third example concerns two gliders deployed at 1-day intervals along the CryoSat-2 track 493, which passed on 27 April 2015. CryoSat-2 SAR data are filtered at $35 \mathrm{~km}$ (see Sect. 3). Figure 9 shows that the two gliders and the CryoSat-2 data detect well the westward-flowing Northern Current near $42.5^{\circ} \mathrm{N}$ as well as an eastward return flow around $41.5^{\circ} \mathrm{N}$. In contrast, the CryoSat-2 data overlay a weak cyclonic eddy centred on $42^{\circ} \mathrm{N}$, which is also apparent in the mapped AVISO data but is not detected by the gliders. The CryoSat-2 data are included in the AVISO maps, so the two products show consistent results, though AVISO is smoother.

The along-track geostrophic currents (Fig. 9b) show that the two gliders, separated by 1 day, observe the same features. However, the peaks in westward flow, detected by the gliders at 42.6 and $42.1^{\circ} \mathrm{N}$, are slightly more intense with the CryoSat- 2 observations and had shifted southward when the altimeter observed them a few days later. Tintin is 1 day in advance of Bonplan-d as they move southward, and the southward shift in the westward flow is also observed between Tintin and Bonplan-d at $42^{\circ} \mathrm{N}$. There is a good alignment of the eastward currents between the three observing systems around $41.7^{\circ} \mathrm{N}$.

In summary, the glider-altimeter comparisons reveal the difficulty in validating the along-track altimetry data with observations that are not exactly co-located in time and space. The relatively slow gliders are able to capture the slowermoving larger eddies, as seen in our example with Jason-2 and highlighted by previous studies (Bouffard et al., 2010). However, the real improvement in altimetric signal-to-noise levels expected with SARAL and CryoSat-2 are not revealed in these glider comparisons, mainly because at the time of these altimeter observations, rather weak signals were de- tected or the small-scale meanders were moving rapidly. In these cases, our observations approach the error levels of the two systems. Small offsets in the structure of the Northern Current could also be introduced by the removal of a mean sea surface from the CryoSat-2 data sets, which could induce errors on these small space scales (up to $80 \mathrm{~km}$ wavelength, Dufau et al., 2016). Although gliders can observe energetic small-scale structures in dedicated campaigns in the Mediterranean Sea (e.g. Bosse et al., 2015), the chance is small that these occur at the precise position and time when the gliders and altimeter tracks coincide. This comparison highlights the difficulty in setting up a validation campaign for altimetric observations of small-scale rapidly moving dynamics.

\section{Co-located HF radar and SARAL altimeter}

HF radar data provide an additional observation of the oceanic surface currents. In comparison to the geostrophic component of the flow obtained with altimetry and gliders, HF radars measure the total surface current, due to balanced geostrophic and unbalanced ageostrophic currents (winddriven, inertial, tidal currents, etc.). The daily data set we used has been processed to remove the HF tides and inertial currents, retaining the geostrophic and wind-driven currents. Figure 10 shows an example of the HF radar total currents for one date, 20 October 2013 near Toulon, with the two coastal radar locations marked. The presence of the strong Northern Current is clearly visible in the 2-D HF radar current vectors, with a central jet only $10 \mathrm{~km}$ wide, the current spanning $20 \mathrm{~km}$ to its edges. This is clearly below the statistical observability limits from the spectral analysis of the three altimeter missions. The offshore extent of the HF radar data is from 25 to $75 \mathrm{~km}$ from the coast, which extends into the coastal band that was excluded from our spectral analysis, as it has frequently "noisy" altimeter data and corrections. The small spatial coverage of the HF radar means that no Jason-2 data cross this region, although we have one SARAL track passing through the centre (Fig. 10) and a number of nonrepeating CryoSat-2 tracks. The angle of the SARAL track shown in Fig. 10 is such that the cross-track geostrophic currents are mainly orientated in the principal direction of the Northern Current. For this date (20 October 2013), the amplitude of the HF radar currents, projected in the altimetric cross-track direction (in red), is similar to the SARAL cross-track currents (in black), reaching $0.7-0.8 \mathrm{~m} \mathrm{~s}^{-1}$ within the Northern Current. Further offshore, the HF radar currents decrease gradually whereas the geostrophic altimetric currents are much weaker outside of the jet. The presence of ageostrophic currents in the HF radar data could contribute to this difference. Our statistical estimate of the spatial observability of SARAL observations in autumn is around $35 \mathrm{~km}$ wavelength (Sect. 3), representing feature structures across the current of around $17 \mathrm{~km}$. Clearly at these scales, 
(a)

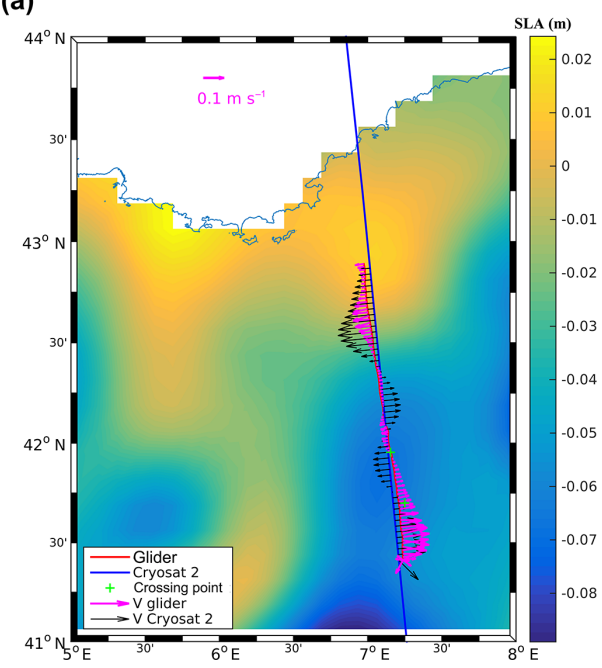

(b)

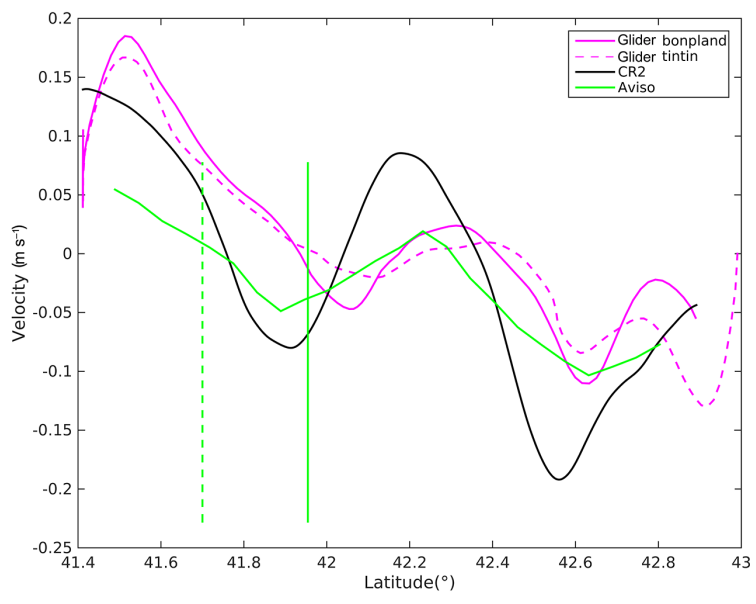

Figure 9. (a) Co-located CryoSat-2 track 493 currents (in black) and glider currents (in pink), overlaid with a satellite SST plot on 27 April 2015. Two gliders, Bonplan-d and Tintin, follow at 1-day intervals. (b) Along-track comparison of geostrophic velocities for the Bonplan-b glider (pink solid), and Tintin (pink dashed) with the filtered CryoSat-2 SAR data in black. Mapped AVISO altimeter data, interpolated back onto the altimeter track, are in green. Green vertical line shows the position when the altimeter data and gliders are co-located. (solid for Bonplan-d; dashed for Tintin). Daily SST fields at $0.02^{\circ}$ resolution from CLS.

the $20 \mathrm{~km}$ wide Northern Current can be observed by the SARAL altimeter.

The advantage of the HF radar data set is its daily 2-D coverage at fine resolution, so we should not have the space-time offsets in the sampling of small-scale features that plagued the glider-altimeter comparisons. The disadvantage is that altimeter data in the last $10-50 \mathrm{~km}$ from the coast are noisy, and the ageostrophic wind-driven component of the HF radar surface currents can be strong here, in the region with strong mistral winds.

We have compared the observability of these near-shore currents with the finer-resolution SARAL altimeter time series, filtered at $35 \mathrm{~km}$ (see Sect. 3). SARAL data are available along this track every 35 days, and Fig. 11 shows the 18-month time series of cross-track surface velocities from the HF radar. The upper panel shows the full time series of HF radar currents projected perpendicular to the altimeter track; the middle panel shows the HF radar currents sampled at the same dates as the SARAL altimeter passes, and spatially sampled at $7 \mathrm{~km}$ as for the $1 \mathrm{~Hz}$ altimeter data. The bottom panel shows the SARAL $1 \mathrm{~Hz}$ geostrophic currents (mean and anomalies), filtered at $35 \mathrm{~km}$. SARAL clearly detects more of the offshore return flow than the HF radar can but covers a similar data range as the HF radar to the coast. Along-track correlations of the HF radar and altimetric currents for this cross-track velocity component are between 0.7 and 0.9 for these 16 tracks, except for four dates, where the correlations drop below 0.5. The RMSE between the crosstrack HF radar current amplitudes and the SARAL current amplitudes is shown in Fig. 12. Dates with low correlations $(<0.5)$ are marked with the vertical dashed line, and these have a higher RMSE. The RMSE is generally lower in the summer months when the wind is lower and increases in winter.

Wind forcing of the ageostrophic currents may explain part of the difference. If we consider the daily time series of HF radar data (Fig. 11a) and extract the outliers in cross-track velocity having $>1 \sigma$ standard deviation from the mean, we find that these outliers are correlated at 0.84 with the crosstrack wind at the same date (not shown). For the dates with weak correlations, wind may play a role for one date (December 2013), but the other dates have relatively low wind. The differences with SARAL are often associated with $10 \mathrm{~km}$ wide structures and close to the coast. This could be due to errors in either measurement system (e.g. for SARAL: the nearshore wave height bias, wet tropospheric corrections, mean sea surface errors) but also from rapid events that are detected by the altimeter $8 \mathrm{~s}$ "snapshot" but viewed differently with the HF radar 1-day averages (rapid meander, internal waves, etc.). Planned future analysis of the higherfrequency radar data and the $40 \mathrm{~Hz}$ altimeter data with appropriate filtering may help elucidate some of these differences.

\section{Discussion}

The along-track altimeter spectral analysis allows us to estimate the mean dynamical scales that can be observed today with different altimeter technology and associated processing, and in different seasons. In winter, when the mixed layers are deepest and the submesoscale is energetic, all of the altimeter missions can observe wavelengths down to 40- 


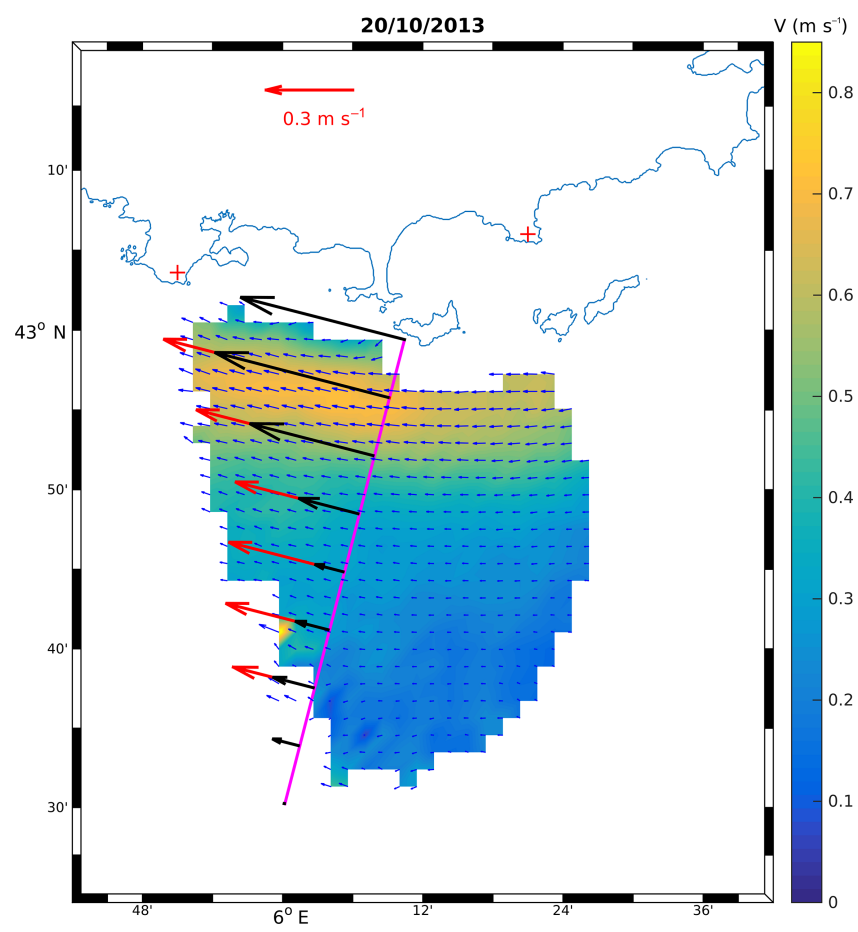

Figure 10. HF radar surface currents near Toulon for one date (20 October 2013); direction with small arrows, current speed is in colour. SARAL track 302 is marked in pink; $1 \mathrm{~Hz}$ cross-track geostrophic currents from SARAL altimetry are in black; the HF radar total currents projected in the altimetric cross-track direction are in red. The current scale of $0.3 \mathrm{~m} \mathrm{~s}^{-1}$ is associated with the projected currents. Positions of the two HF radar sites are marked with the red crosses on land.

$50 \mathrm{~km}$ (individual feature diameters of 20-25 km). In summer when the submesoscales are weaker, SARAL can detect ocean scales down to $35 \mathrm{~km}$ wavelength, whereas the higher noise from Jason-2 and CryoSat-2 blocks the observation of scales less than $50-55 \mathrm{~km}$ wavelength.

This is a statistical view. There are limits in applying this too assiduously, especially as these statistics are calculated from relatively short records for SARAL, and only 13 months of reprocessed SAR data for CryoSat-2. We chose to analyse the longest time series possible for the seasonal calculations since the records are relatively short. However, entire years should be analysed to remove any sampling biases in these statistics. Given the long repeat time for CryoSat-2, we also measure different geographical regions in each season, which can introduce biases in our basin-scale averages. Interannual variations also occur in the dynamics in response to interannual atmospheric changes, which can lead to different deep convection events from one season to another (Adloff et al., 2015). Analysing a longer time series of SARAL and CryoSat data should improve the significance of these early results.

One application of this type of analysis is to improve the altimetric data post-processing to be adapted to the regional conditions. Today, along-track filtering is applied in a similar way to all altimeter missions to reduce the instrument and geophysical noise. Since consecutive altimeter points are laid down spatially, data are filtered spatially along the track to reduce this noise. Standard filtering in the AVISO along-track products DT2010 ranges from $55 \mathrm{~km}$ wavelength at high latitudes to around $250 \mathrm{~km}$ in the tropics (Dibarboure et al., 2011). The new AVISO products DT2014 apply lower along-track smoothing at $65 \mathrm{~km}$ wavelength, globally and for all missions (Pujol et al., 2016). This study suggests that the along-track filtering may be tuned in a regional study to be better adapted to the local dynamics and noise conditions. Thus in the NW Mediterranean Sea, filtering of Jason-2 data could vary seasonally from $50 \mathrm{~km}$ in winter to $60 \mathrm{~km}$ in autumn and spring (or a conservative $60 \mathrm{~km}$ yearround). SARAL could have a finer-scale along-track filtering applied, to retain wavelengths greater than $35 \mathrm{~km}$ in summerautumn and $45 \mathrm{~km}$ in winter. A filter cutoff of $50 \mathrm{~km}$ yearround could be suitable for CryoSat-2. Knowing how this statistical signal-to-noise ratio varies from one mission to another, and seasonally, is very useful for regional applications, for local process studies or for data assimilation.

The in situ validation remains very limited in space and time and did not allow us to confirm whether these smaller scales are realistic ocean features. For the glider comparison with SARAL, small-scale structures were detected by both systems, but their rapid movement prevented us from giving a precise along-track co-location except for the short scales close to the temporal crossing point. Indeed, for advective dynamics to be resolved correctly, they should conform to the Friedrichs-Lewy condition, i.e. $U \Delta t / \Delta x<1$. If we follow small structures with typical advection speeds of $U=0.3 \mathrm{~m} \mathrm{~s}^{-1}$ (typical of the Northern Current), then we need time differences, $\Delta t$, of less than 1.35 days to resolve the smaller SARAL wavelengths at $35 \mathrm{~km}$, and within 2 days for the Jason-2 and CryoSat-2 data to resolve $50 \mathrm{~km}$ wavelength structures. With the slow-moving gliders, we can only cover $30 \mathrm{~km}$ per day, and so our along-track intercomparisons should be limited to the $\pm 30 \mathrm{~km}$ around the altimeter-glider crossing point. This places a very strong constraint on our in situ validation.

The SARAL intercomparison with the Toulon HF radar data was quite promising. Despite the apparent nearshore errors in the SARAL data, and the periods with strong wind-driven currents, the correlation between the SARAL geostrophic currents and HF radar total currents remained high. The position of the Toulon HF radar helps, as the observations are centred on the Northern Current, in a region where the current is strongly steered by bathymetry, and the geostrophic component is dominant. This example indicates that a strong coastal current, with a high signal-to-noise ratio, can be detected by satellite altimetry, even at $20 \mathrm{~km}$ from the coast. Improvements are still needed to reduce the altimetric errors in the nearshore region, and to compare the CryoSat-2 SAR current observations with the HF radar data. 
(a)
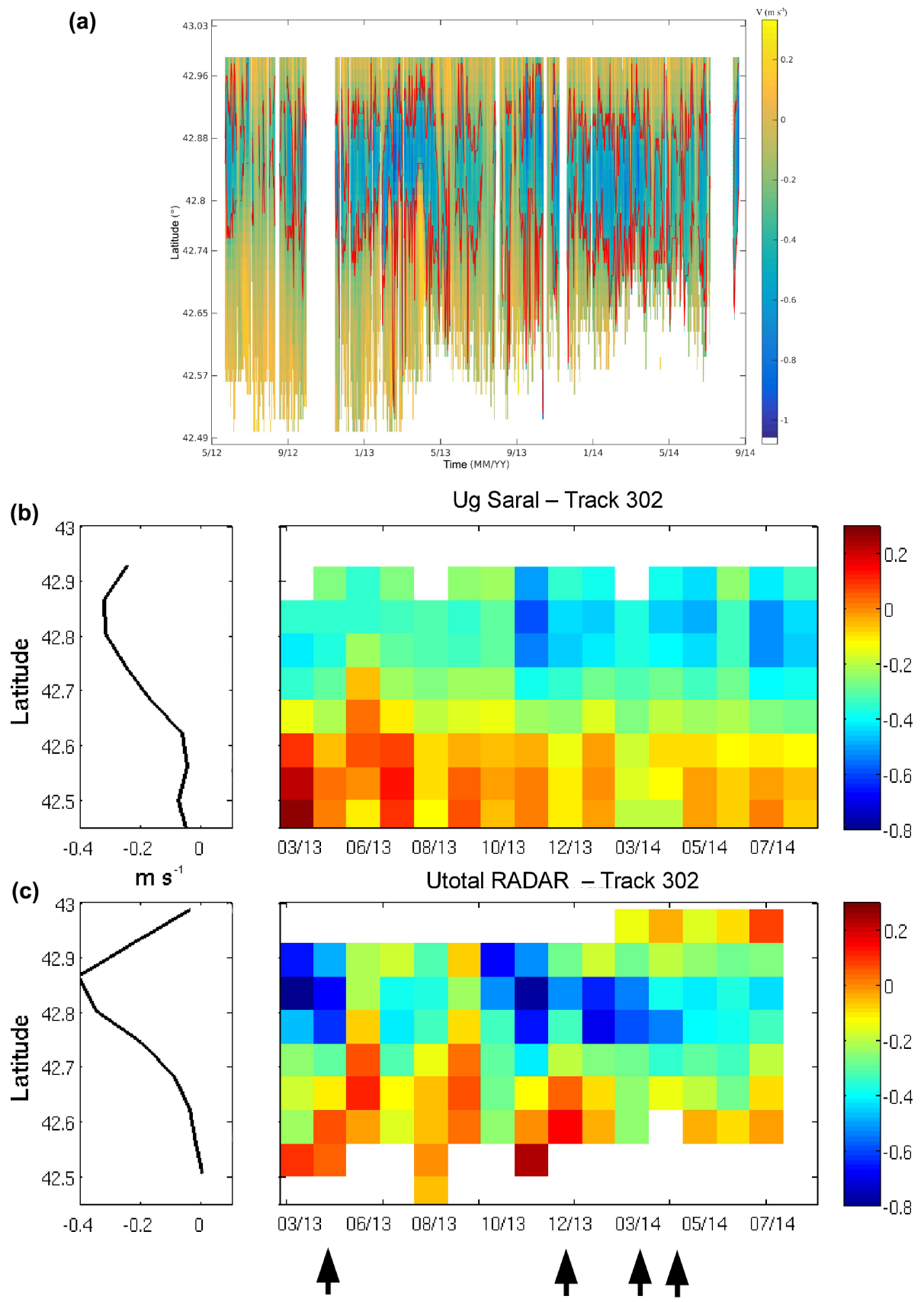

Figure 11. (a) Upper panel: 18-month time series of daily HF radar surface currents projected in the cross-track direction of the SARAL ground track. Red contours at $-0.3 \mathrm{~m} \mathrm{~s}^{-1}$ aid to delimit the westward Northern Current position. (b) Middle panel: extraction of these daily HF radar currents at the day of the SARAL observations. The temporal mean value is shown on the left. (c) Bottom panel: cross-track geostrophic currents from the SARAL altimeter data, filtered at $35 \mathrm{~km}$ wavelength. Arrows mark the dates with low correlations $<0.5$.

This good intercomparison suggests that HF radar data may be combined with altimetry to extend the observations (duration and offshore extent) of the Northern Current and its recirculation near Toulon.

Another potential way to cross-validate the feature scales observed by the different altimeter missions is to use the crossover points between different missions. Figure 1 shows that there are many crossover points during this analysis period, especially from CryoSat-2 on its long-repeat 369-day orbit and even from Jason-1, which moved into a long-repeat 406-day geodetic orbit from April 2012 to 1 July 2013. Our analyses of the small, fast-moving features in this paper indicate that we really need crossover measurements overlapping within 1-2 days to capture these fine-scale features. These 


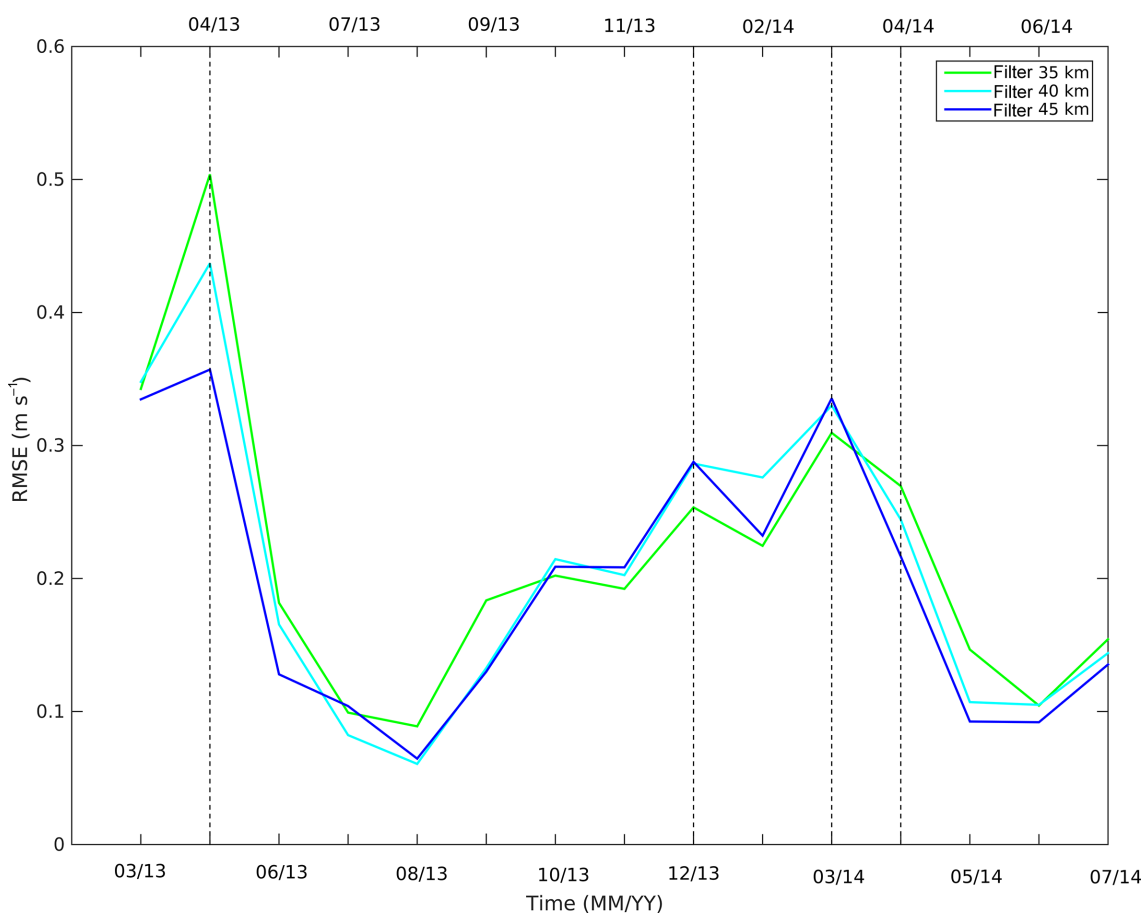

Figure 12. RMSE between the cross-track HF radar current amplitudes and the SARAL current amplitudes. Dates with low correlations $(<0.5)$ are marked with the vertical dashed line.

multi-altimeter overlapping passes are also interesting for the missions on a similar inclination, since their overlapping sections can be quite long. For example, SARAL and CryoSat may have long overlapping sections with a time difference of less than 2 days (see Fig. 1). Similar long sections may be available from the Jason-1 geodetic mission and Jason2. At present, we are developing the code to calculate the crossovers from multi-satellite passes and select the passes based on their time differences. This analysis will be performed as part of our ongoing work in this region.

For the future altimetric missions, finer spatial sampling and lower noise levels should continue, with Sentinel-3 in global SAR mode launched in early 2016, and SWOT providing 2-D interferometric SAR heights and images and an order of magnitude lower noise in 2021. Similar wavenumber spectral analysis techniques could be applied to estimate the noise levels and observable spatial scales with these new missions. This study illustrates that the difficulties in setting up an adequate in situ validation for the small-scale, rapidly evolving dynamics will remain a challenge to resolve in the future.

\section{Data availability}

Altimeter data: the unfiltered along-track Jason-2 and SARAL altimeter SLA data sets are available from the AVISO website (http://aviso.altimetry.fr/) and the CMEMS website (http://marine.copernicus.eu/). The unfiltered along- track CryoSat-2 CPP data are an experimental product provided by the CNES. These Level 2 (GDR) input data are provided by CNES, ESA, and NASA. CryoSat SLAs are calculated relative to a gridded mean sea surface (MSS_CLS2011, http://www.aviso.altimetry.fr/en/data/ products/auxiliary-products/mss.html).

Glider data are available as part of the MOOSE project (http://www.moose-network.fr/gliders).

HF radar data are also available as part of the MOOSE observing system (http://hfradar.univ-tln.fr/HFRADAR).

Author contributions. This work was carried out by Alice Carret as part of her master's programme. Rosemary Morrow supervised the work and prepared the manuscript with contributions from all co-authors. Guillaume Valladeau and Francois Boy provided cosupervision. Florence Birol and Fernando Nino provided support with the analysis. Celine Bachelier processed the glider data and Bruno Zakardjian the HF radar data.

Competing interests. The authors declare that they have no conflict of interest.

Acknowledgement. This work was funded by an OSTST CNES TOSCA grant. The glider and HF radar data were funded as part of the French MOOSE Mediterranean observing system programme, with additional financial support from CNES as part 
of the Comsom glider campaign. We gratefully acknowledge the constructive comments by two reviewers and the editor, which helped to improve the manuscript.

Edited by: J. M. Huthnance

Reviewed by: A. Sánchez Román and one anonymous referee

\section{References}

Adloff, A., Somot, S., Sevault, F., Jorda, G., Aznar, R., Déqué, M., Herrmann, M., Marcos, M., Dubois, C., Padorno, E., AlvarezFanjul, E., and Gomis, D.: Mediterranean Sea response to climate change in an ensemble of 21 st century scenarios, Clim. Dynam., 45, 2775, doi:10.1007/s00382-015-2507-3, 2015.

Birol, F. and Delebecque, C.: Using High Sampling Rate $(10 / 20 \mathrm{~Hz})$ Altimeter Data for the Observation of Coastal Surface Currents: A Case Study over the Northwestern Mediterranean Sea, J. Marine Syst., 129, 318-333, doi:10.1016/j.jmarsys.2013.07.009, 2014.

Birol, F. and Niño, F.: Ku and Ka-Band Altimeter Data in the Northwestern Mediterranean Sea, Mar. Geod., 38, 313-327, doi:10.1080/01490419.2015.1034814, 2015.

Birol, F., Cancet, M., and Estournel, C.: Aspects of the seasonal variability of the Northern Current (NW Mediterranean Sea) observed by altimetry, J. Marine Syst., 81, 297-311, 2010.

Bosse, A., Testor, P., Mortier, L., Prieur, L., Taillandier, V., D'Ortenzio, F., and Coppola, L.: Spreading of Levantine Intermediate Waters by submesoscale coherent vortices in the northwestern Mediterranean Sea as observed with gliders, J. Geophys. Res.-Oceans, 120, 1599-1622, doi:10.1002/2014JC010263, 2015.

Bouffard, J., Vignudelli, S., Cipollini, P., and Ménard, Y.: Exploiting the potential of an improved multimission altimetric data set over the coastal ocean, Geophys. Res. Lett., 35, L10601, doi:10.1029/2008GL033488, 2008.

Bouffard, J., Pascual, A., Ruiz, S., Faugère, Y., and Tintoré, J.: Coastal and mesoscale dynamics characterization using altimetry and gliders: A case study in the Balearic Sea, J. Geophys. Res., 115, C10029, doi:10.1029/2009JC006087, 2010.

Bouffard, J., Roblou, L., Birol, F., Pascual, A., Fenoglio-Marc, L., Cancet, M., Morrow, R., and Ménard, Y.: Introduction and assessment of improved coastal altimetry strategies: case study over the North Western Mediterranean Sea, Chapter 12, in: Coastal Altimetry, edited by: Vignudelli, S., Kostianoy, A. G., Cipollini, P., and Benveniste, J., Springer-Verlag Berlin Heidelberg, 578 pp., doi:10.1007/978-3-642-12796-0_12, 2011.

Boy, F., Desjonquères, J.-D., Picot, N., Moreau, T., and Raynal, M.: CryoSat-2 SAR-Mode Over Oceans: Processing Methods, Global Assessment, and Benefits, IEEE Trans. Geosci. Remote Sens., 55, 148-158, doi:10.1109/TGRS.2016.2601958, 2017.

Chelton, D. B., Schlax, M. G., and Samelson, R. M.: Global observations of nonlinear mesoscale eddies, Prog. Oceanogr., 91, 167-216, 2011.

Dibarboure, G., Pujol, M.-I., Briol, F., Le Traon, P. Y., Larnicol, G., Picot, N., Mertz, F., and Ablain, M.: Jason-2 in DUACS: Updated System Description, First Tandem Results and Impact on Processing and Products, Mar. Geod., 34, 214-241, doi:10.1080/01490419.2011.584826, 2011.
Dibarboure, G., Boy, F., Desjonqueres, J. D., Labroue, S., Lasne, Y., Picot, N., Poisson, J. C., and Thibaut, P.: Investigating Short-Wavelength Correlated Errors on Low-Resolution Mode Altimetry, J. Atmos. Ocean. Tech., 31, 1337-1362, doi:10.1175/JTECH-D-13-00081.1, 2014.

Dufau, C., Orsztynowicz, M., Dibarboure, G., Morrow, R., and Le Traon, P.-Y.: Mesoscale resolution capability of altimetry: Present and future, J. Geophys. Res.-Oceans, 121, 4910-4927, doi:10.1002/2015JC010904, 2016.

Durand, F., Marin, F., Fuda, J. L., and Terre, T.: The East Caledonian Current : A Case Example for the Intercomparison between AltiKa and In Situ Measurements in a Boundary Current, Mar. Geod., 1-22, 2016.

Fu, L.-L.: On the wavenumber spectrum of oceanic mesoscale variability observed by the Seasat altimeter, J. Geophys. Res.Oceans, 88, 331-334, 1983.

Grilli, F. and Pinardi, N.: The computation of Rossby radii between external forcing mechanisms and internal of deformation for the Mediterranean Sea, MTP News, 6, 4-5, 1998.

Guihou, K., Marmain, J., Ourmières, Y., Molcard, A., and Zakardjian, B.: Forget P., A case study of the mesoscale dynamics in the North-Western Mediterranean Sea: a combined data-model approach, Ocean Dynam., 63, 793-808, doi:10.1007/s10236-0130619-z, 2013.

Herrmann, M., Somot, S., Sevault, F., Estournel, C., and Déqué, M.: Modeling deep convection in the Northwestern Mediterranean Sea using an eddy-permitting and an eddy-resolving model: case study of winter 1986-87, J. Geophys. Res., 113, C04011, doi:10.1029/2006JC003991, 2008.

Lambin, J., Morrow, R., Fu, L.-L., Willis, J. K., Bonekamp, H., Lillibridge, J., Perbos, J., Zaouche, G., Vaze, P., Bannoura, W., Parisot, F., Thouvenot, E., Coutin-Faye, S., Lindstrom, E., and Mignogno, M.: The OSTM/Jason-2 Mission, Mar. Geod., 33, 425,2010 .

Lebeaupin Brossier, C., Bastin, S., Béranger, K., and Drobinski, P. Regional mesoscale air-sea coupling impacts and extreme meteorological events role on the Mediterranean Sea water budget, Clim. Dynam., 44, 1029-1051, 2015.

Le Traon, P. Y., Klein, P., Hua, B. L., and Dibarboure, G.: Do Altimeter Wavenumber Spectra Agree with the Interior or Surface Quasigeostrophic Theory?, J. Phys. Oceanogr., 38, 1137-1142, doi:10.1175/2007JPO3806.1, 2008.

Millot, C.: Circulation in the Western Mediterranean Sea, J. Mar. Syst., 20, 423-442, 1999.

Morrow, R., Birol, F., Griffin, D., and Sudre, J.: Divergent pathways of cyclonic and anti-cyclonic ocean eddies, Geophys. Res. Lett., 31, L24311, doi:10.1029/2004GL020974, 2004.

Pascual, A., Pujol, M.-I., Larnicol, G., Le Traon, P.-Y., and Rio, M.-H.: Mesoscale mapping capabilities of multisatellite altimeter missions: First results with real data in the Mediterranean Sea, J. Mar. Syst., 65, 190-211, doi:10.1016/j.jmarsys.2004.12.004, 2006.

Pujol, M.-I. and Larnicol, G.: Mediterranean sea eddy kinetic energy variability from 11 years of altimetric data, J. Mar. Syst., 58, 121-142, 2005.

Pujol, M.-I., Faugére, Y., Taburet, G., Dupuy, S., Pelloquin, C., Ablain, M., and Picot, N.: DUACS DT2014: the new multimission altimeter data set reprocessed over 20 years, Ocean Sci., 12, 1067-1090, doi:10.5194/os-12-1067-2016, 2016. 
Quentin, C., Barbin, Y., Bellomo, L., Forget, P., Gagelli, J., Grosdidier, S., Guerin, C.-A., Guihou, K., Marmain, J., Molcard, A., Zakardjian, B., Guterman, P., and Bernardet, K.: HF radar in French Mediterranean Sea: an element of MOOSE Mediterranean Ocean Observing System on Environment, OCOSS'2013 Proceedings, 25-30, 2013.

Ray, C., Martin-Puig, C., Clarizia, M. P., Ruffini, G., Dinardo, S., Gommenginger, C., and Benveniste, J.: SAR altimeter backscattered waveform model, Trans. Geosci. Remote Sens., 53, 911919, doi:10.1109/TGRS.2014.2330423, 2015.

Rio, M.-H., Pascual, A., Poulain, P.-M., Menna, M., Barceló, B., and Tintoré, J.: Computation of a new mean dynamic topography for the Mediterranean Sea from model outputs, altimeter measurements and oceanographic in situ data, Ocean Sci., 10, 731-744, doi:10.5194/os-10-731-2014, 2014.

Robinson, I. S.: Discovering the ocean from Space. The unique applications of satellite oceanography, Springer, 638 pp., doi:10.1007/978-3-540-68322-3, 2010.
Stammer, D.: Global characteristics of ocean variability estimated from regional TOPEX/POSEIDON altimeter measurements, J. Phys. Oceanogr., 27, 1743-1769, 1997.

Verron, J., Sengenes, P., Lambin, J., Noubel, J., Steunou, N., Guillot, A., Picot, N., Coutin-Faye, S., Sharma, R., Gairola, R. M., Raghava Murthy, D. V. A., Richman, J. G., Griffin, D., Pascual, A., Rémy, F., and Gupta, P. K.: The SARAL/AltiKa altimetry satellite mission, Mar. Geod., 38, 221, doi:10.1080/01490419.2014.1000471, 2015.

Xu, Y. and Fu, L.-L.: Global Variability of the Wavenumber Spectrum of Oceanic Mesoscale Turbulence, J. Phys. Oceanogr., 41, 802-809, doi:10.1175/2010JPO4558.1, 2011.

$\mathrm{Xu}, \mathrm{Y}$. and Fu, L.-L.: The Effects of Altimeter Instrument Noise on the Estimation of the Wavenumber Spectrum of Sea Surface Height, J. Phys. Oceanogr., 42, 2229-2233, doi:10.1175/JPO-D12-0106.1, 2012. 